Special Hospitals Division of the London County Council and to Mr. Arnold Sorsby for his help and encouragement.

\title{
REFERENCES
}

1. Clarke, E.-Ophthal. Rev., Vol. XIII, p. 345, London, 1894.

2. Sorsby, A.-Brit. Med. Jl., Vol. II, p. 730, 1933.

3. Sorsby, A.-London County Council, Annual Report for 1935, Vol. IV, iii, p. 55.

4. Defective Vision in School Children, Report of the Committee of Enquiry. Great Britain Board of Education. His Majesty's Stationery Office, 1931.

5. McIlroy, J. H.-London County Council Annual Report, Vol. III, p. 86, 1928.

\section{A "PIN" EYE-DROPPER}

BY

\section{N. BISHOP HARMAN}

LONDON

OILY preparations of alkaloids for the treatment of eye diseases are in many cases preferable to watery solutions. Oily preparations keep better and, in some cases, they are more effective. For example, eserine in castor oil in the palliative treatment of chronic glaucoma, or homatropine in refraction work. Oily preparations are perhaps less used than they might be owing to their messiness. This arises from too much being put into the eye by using a glass

rod or dropper. The "pin" eye-dropper meets this difficulty. It is an ordinary domestic pin fixed into a suitable handle, and the whole chromium plated. If the head only of the pin be dipped into the oil it will lift a globule of the right volume, which by a touch on the mucosa of the lower lid is transferred to the eye. The dropper can be boiled. It is made by Messrs. W. Martindale, of New Cavendish Street, W.1.

\section{A BI-CYLINDRICAL TYPE READER}

BY

\author{
G. B. Lowe, D.O.(Oxon.) \\ BEXHILL-ON-SEA
}

INCREASING the height of a letter form is well known to increase legibility owing to the reading sight travelling along the top of the print. When the lower half of a line of print only is seen, the line can scarcely be read. 
This reading glass constructed for me by Messrs. Rayner stretches the type vertically, and so increases legibility. The glass is useful for those with damaged macular perception, particularly for the aged and those with obstructions in the media, whether in cornea, lens, or vitreous. It consists of two plano-cylinders of six dioptres each, lying back to back on the horizontal, giving an effective power of twelve dioptres. The handle of the glass is set obliquely to allow

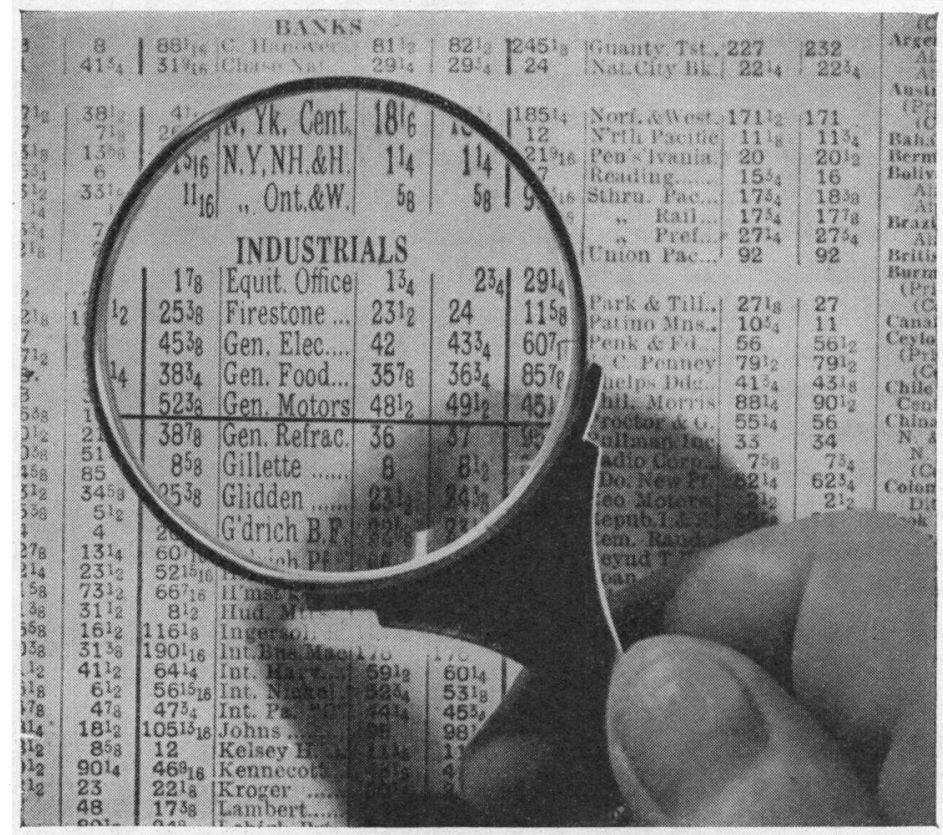

an easy wrist hold. The black etched line across the lower third of the glass is an additional guide for holding it properly so that the print is seen truly vertical when the black line rules along the type below the reading level. At first the two cylinders were mounted with an air space between, but in practice it was found that a solid piece of glass prevented the possibility of the cylinders getting out of alignment, and also tended to decrease weight.

Messrs. Rayner have kindly supplied me with an illustration which explains the reader in action. 